\title{
Effect of dietary level of maize- and rye distiller dried grains with solubles on nutrient utilization and digesta viscosity in laying hens
}

\author{
S. Świątkiewicz ${ }^{1}$ and J. Koreleski \\ National Research Institute of Animal Production, \\ Department of Animal Nutrition and Feed Science \\ 32-083 Balice, Poland
}

(Received 15 July 2007; revised version 6 November 2007; accepted 21 November 2007)

\begin{abstract}
An experiment on 55 Lohman Brown hens examined the effect of different dietary levels of maize- and rye distillers dried grains with solubles (mDDGS and rDDGS, respectively) on nutrient digestibility, content of metabolizable energy in the diet and balance of nitrogen, calcium, phosphorus, and zinc. Experimental diets were isocaloric and isonitrogenous and contained 0, 5, 10, 15, or $20 \%$ mDDGS or rDDGS. Diets with $20 \%$ mDDGS or rDDGS were also supplemented with NSPhydrolysing enzymes.

It was found that 5, 10 or $15 \%$ mDDGS in a diet had no effect on apparent digestibility of nutrients, dietary metabolizable energy content, or balance of $\mathrm{N}, \mathrm{Ca}$ and $\mathrm{Zn} ; 20 \%$ mDDGS decreased the digestibility of crude fat and lowered the level of metabolizable energy in the diet, whereas 15 or $20 \%$ rDDGS negatively affected organic matter and crude fat digestibility and the dietary metabolizable energy level. A 15 or $20 \%$ inclusion of mDDGS or rDDGS had, however, a positive effect on phosphorus balance. Addition of feed enzymes increased nutrient utilization in diets containing $20 \%$ DDGS.
\end{abstract}

KEY WORDS: laying hens, maize DDGS, rye DDGS, nutrient digestibility, metabolizable energy

\section{INTRODUCTION}

Distillers dried grains with solubles (DDGS) is a by-product of ethanol production. Growing interest in fuel ethanol production will lead to increases in the amounts of DDGS available to the feed industry. In our previous studies it was

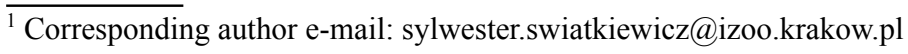


concluded that maize- and rye DDGS (mDDGS and rDDGS) are useful feed ingredients for laying hens (Świątkiewicz and Koreleski, 2006a,b). Dietary levels up to $15 \%$ mDDGS and $10 \%$ rDDGS did not unfavourably affect laying performance, egg quality, and flavour of boiled eggs when were used in hens from 26 to 68 weeks of age. Inclusion of mDDGS in the diet positively influenced egg yolk colour. High dietary levels of DDGS (15\% rDDGS and 20\% mDDGS) did, however, negatively affect laying rate and feed conversion. Similar conclusions on the use of maize DDGS in laying hen diets were drawn by Lumkins et al. (2005) and Roberson et al. (2005).

During fermentation, cereal starch is converted to ethanol and $\mathrm{CO}_{2}$ and the concentration of the remaining nutrients in DDGS increases 2-3-fold, so DDGS contains high levels of non-starch polysaccharides (NSP). For this reason, performance reduction in hens fed diets with high DDGS contents could be a result of decreased nutrient utilization. The aim of our experiment was to determine the effect of different levels of mDDGS or rDDGS in diets for laying hens on nutrient digestibility, metabolizable energy content, balance of nitrogen, calcium, phosphorus, zinc, and on digesta viscosity.

\section{MATERIAL AND METHODS}

The experiment was carried out on 55 Lohman Brown laying hens at 39 weeks of age. The experimental design consisted of 11 treatments with 5 replicates (birds) each. Hens were offered water and feed ad libitum and were exposed to a 14 L:10 D lighting schedule, with the dark period at night.

Prior to formulating experimental diets it was determined (AOAC, 1990) that mDDGS and rDDGS contain 35.3 and $33.8 \%$ crude protein, 3.9 and $3.6 \%$ crude fat, 10.8 and $11.9 \%$ crude fibre, 1.7 and $1.5 \%$ crude ash, 0.64 and $0.67 \%$ Lys, 0.68 and $0.62 \%$ Met, 0.08 and $0.07 \% \mathrm{Ca}, 0.543$ and $0.495 \% \mathrm{P}$, respectively.

All experimental diets were isocaloric and isonitrogenous and contained different levels $(0,5,10,15$ or $20 \%)$ of mDDGS or rDDGS. The diets with the highest level of mDDGS or rDDGS were also supplemented with NSP-hydrolysing enzymes (Table 1). The experimental diets were fed to hens before the beginning of the balance study (from 26 weeks of age).

At 39 weeks of age the hens were divided into individual balance cages. After a one-week adaptation period, total collection of excreta was carried out during 5 days and feed consumption for each hen was recorded. Excreta were stored in plastic bags at $-20^{\circ} \mathrm{C}$ for three weeks and after thawing were dried at $50^{\circ} \mathrm{C}$ to a constant weight, weighed, and finely ground. The proximate composition of diets and excreta was analysed by standard procedures (AOAC, 1990), gross energy, by 


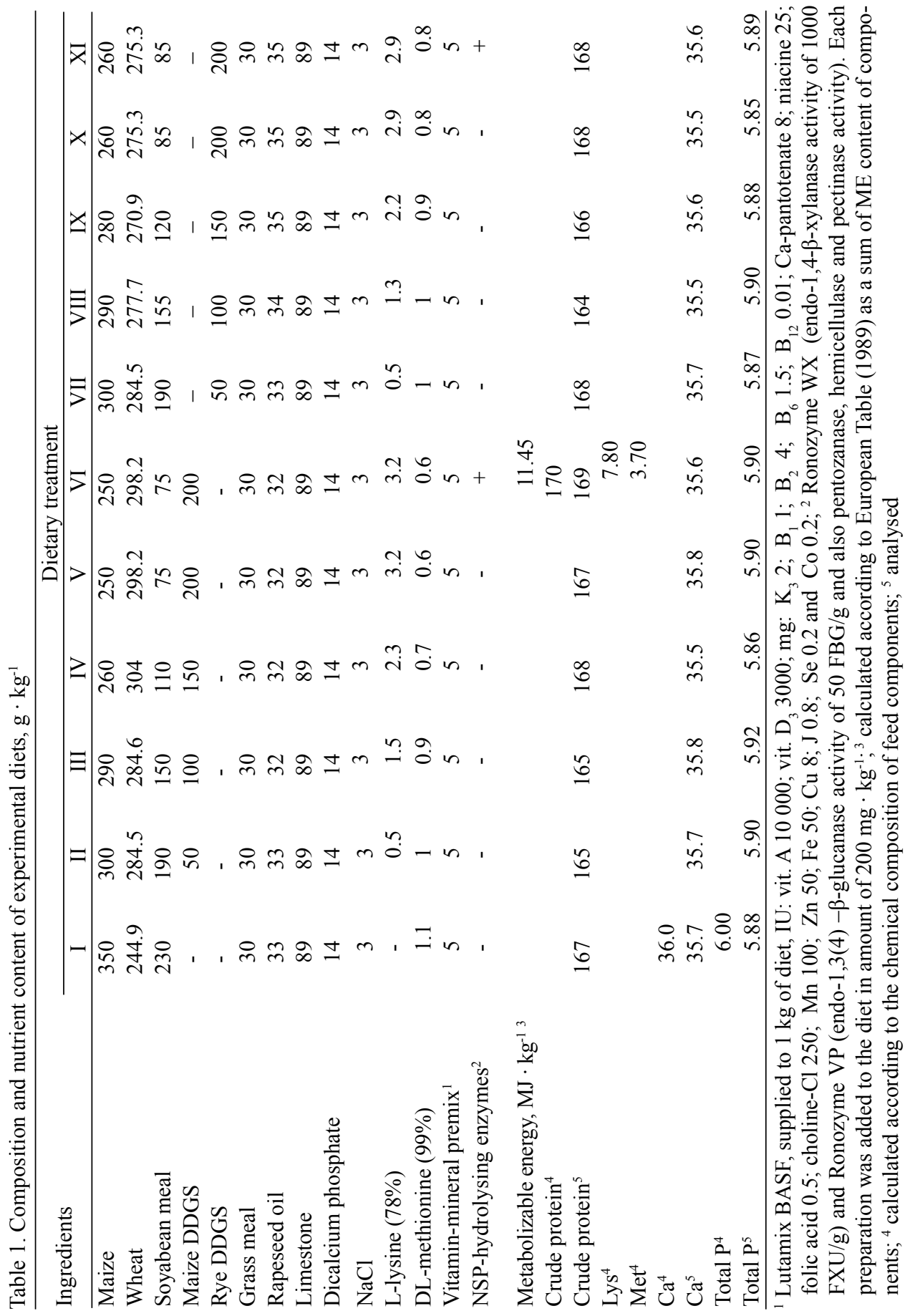


using an adiabatic oxygen bomb calorimeter, total phosphorus, calorimetrically by the molibdeno-vanadate method (AOAC, 1990), Ca and Zn, by flame atomic absorption spectrophotometry (AOAC, 1990). The total tract apparent digestibility of organic matter, crude fat and nitrogen-free extractives, metabolizity coefficient for apparent metabolizable energy corrected for nitrogen retention, and balances of nitrogen, calcium, phosphorus and zinc were calculated using the obtained data.

After completion of the balance trial, 3 hens each from groups I, III, IV, V, VI, VIII, X and XI were killed by cervical dislocation. Whole intestines were removed and total intestinal contents from the upper parts of the intestines (between the gizzard and Meckel's diverticulum) were collected and centrifuged at $5000 \mathrm{~g}$ for $10 \mathrm{~min}$. Viscosity of the supernatant was measured on a capillary viscometer at $37^{\circ} \mathrm{C}$.

In DDGS samples the contents of simple sugars (arabinose, xylose, mannose, galactose and glucose) in NSP were determined using a gas HP 5890 chromatograph (Englyst and Cummings, 1984). Total and insoluble $\beta$-glucans were analysed using the Aman and Graham procedure (1987).

Data were subjected to one-way analysis of variance. The significance of differences between means was determined by Duncan's multiple range test with the use of the Statistica 5.0 PL software package. Two statistical analyses were performed separately for evaluation of the effects of mDDGS and rDDGS on the studied parameters.

\section{RESULTS AND DISCUSSION}

Maize DDGS contained $26.5 \%$ total non-starch polysaccharides $(3.55 \%$ soluble and 23.5 insoluble NSP), $21.5 \%$ arabinoxylans and $0.32 \% \beta$-glucans. The level of NSP in rDDGS was higher: $29.0 \%$ total non-starch polysacaccharides (4.65\% soluble and 24.4 insoluble NSP), $23.3 \%$ arabinoxylans and $1.17 \%$ $\beta$-glucans. The DDGS used in the experiment, especially rDDGS, contained considerable amounts of NSP. For comparison the level of total NSP and arabinoxylans in rye grain, analysed in our earlier experiment (Świątkiewicz et al., 2001), was 2-3 times lower than in the studied DDGS.

The average laying rate during the balance assay was $96.5 \%$, daily mass of eggs, $59.5 \mathrm{~g} / \mathrm{hen} /$ day, feed conversion for $1 \mathrm{~kg}$ of eggs, $1.97 \mathrm{~kg}$, and feed conversion for $1 \mathrm{egg}, 121 \mathrm{~g}$ of feed (Table 2). Dietary inclusion levels of mDDGS had no effect on these parameters, but in hens fed the diet with $20 \%$ rDDGS, worsening of laying performance and feed conversion was noted $(\mathrm{P} \leq 0.05)$. The results of our previous experiments (Świątkiewicz and Koreleski, 2006 a,b), obtained for 


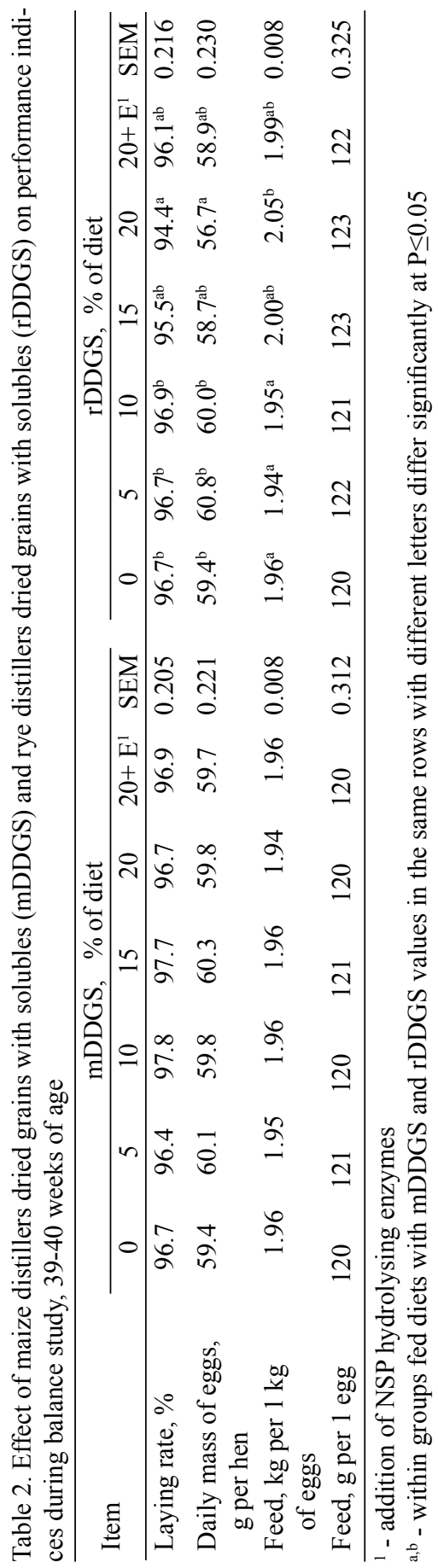


the whole laying cycle (26-68 weeks of age) show that the decrease in laying performance could also have been caused by $20 \%$ mDDGS and $15 \%$ rDDGS in the diet, especially in the second phase of the laying cycle. Lumpkins et al. (2005) found no significant difference in laying performance when hens were fed diets containing 0 or $15 \%$ mDDGS.

The results from the balance assay are summarized in Table 3. There was no difference between treatments in apparent digestibility of nitrogen-free extractives in total digestive tract. The dietary inclusion level of mDDGS had no effect on organic matter digestibility, but in the treatment with $20 \%$ mDDGS, a decrease in crude fat digestibility and metabolizable energy of the diet in comparison with the control group was found $(\mathrm{P} \leq 0.05)$. In contrast with our findings, Spiehs et al. (1999) reported an increase in metabolizable energy when 10 or $20 \%$ mDDGS was included in a pig diet, but in a later experiment (Spiehs et al., 2000), a dietary level of $20 \%$ mDDGS had no effect on energy utilization in pigs.

In hens fed the diet with $20 \%$ rDDGS, the digestibility of organic matter was significantly reduced as compared with the control group (Table 3). A decrease in fat digestibility and in the percentage of $\mathrm{AME}_{\mathrm{N}}$ in gross energy was observed when the diet contained 15 or $20 \%$ rDDGS $(\mathrm{P} \leq 0.05)$. In an experiment on growing pigs, Nyachoti et al. (2005) showed that wheat DDGS had a significantly lower digestibility of dry matter, gross energy and crude protein as compared with wheat. This may correspond with the decrease in nutrient digestibility in treatments with a high dietary level of rDDGS observed in our experiment.

Addition of NSP hydrolyzing enzymes to the diet positively affected nutrient utilization and there was no difference in nutrient digestibility and metabolizability coefficients between the control treatment and hens fed diets with $20 \%$ mDDGS or rDDGS supplemented with the enzyme preparation (Table 3). Dietary inclusion levels of mDDGS or rDDGS did not significantly affect intestinal digesta viscosity, however, viscosity was numerically higher in treatments with $20 \%$ DDGS than in the control group. Supplementation of 20\% DDGS diets with enzymes numerically decreased digesta viscosity, but this effect was not confirmed statistically (Table 3 ).

The results of chemical analysis of NSP fractions in DDGS and the positive effect of enzymes could suggest that the main reason for reduced nutrient digestibility of diets with high levels of DDGS is the considerable amount of non-starch polysaccharides in this by-product. Similar results were obtained by Pan et al. (1998) and Lazaro et al. (2003), who reported that supplementation of diets containing high levels of cereals rich in NSP with NSP-hydrolysing enzymes had a positive influence on dry matter and fat digestibility, dietary $\mathrm{AME}_{\mathrm{N}}$ content and digesta viscosity. Jaroni et al. (1999) found, however, no beneficial effect on digesta viscosity or protein and fat digestibility in hens when diets containing 8 or $16 \%$ of wheat middlings were supplemented with xylanase. Smulikowska et al. 


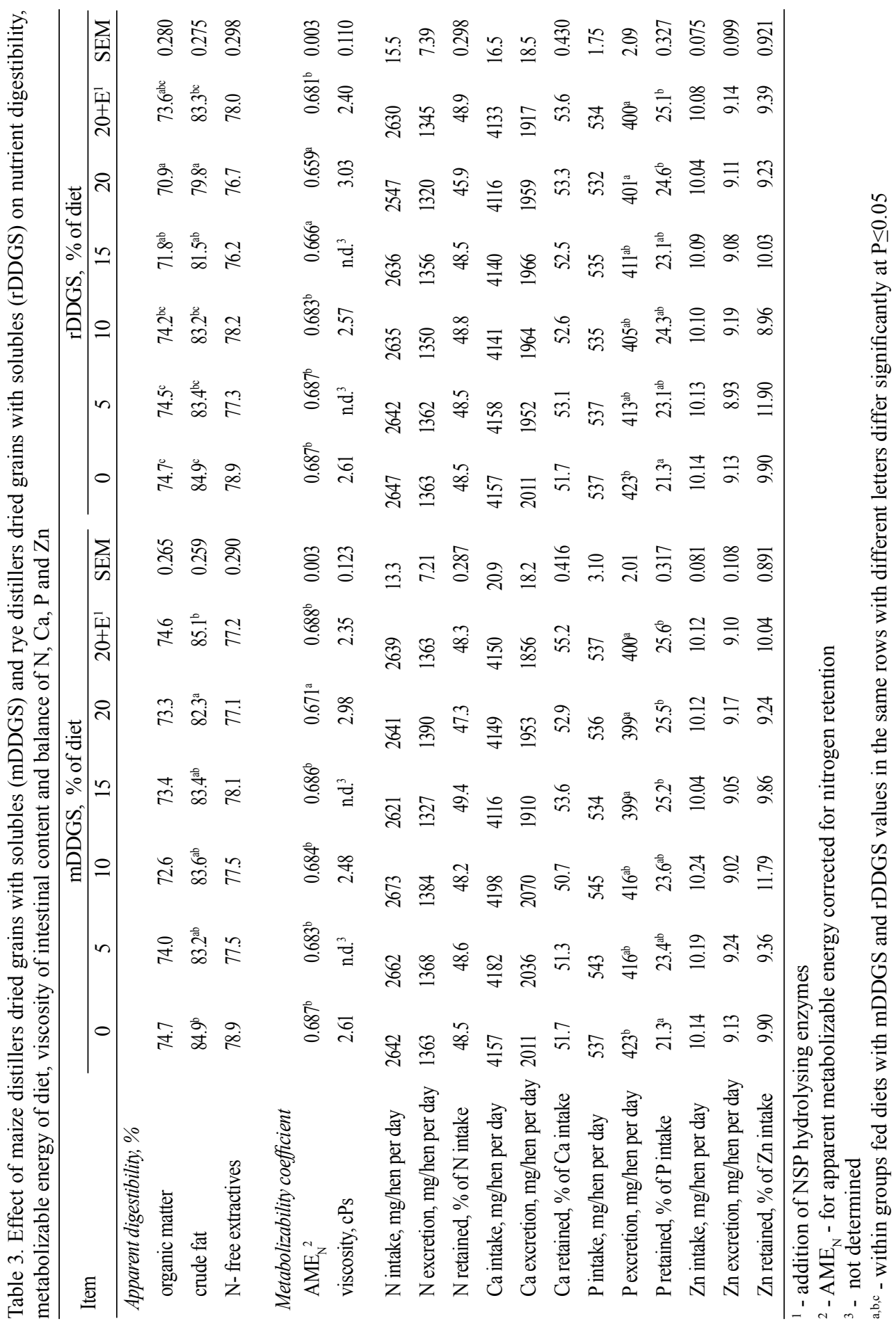


(1997) found that NSP-hydrolysing enzymes decreased intestinal digesta viscosity of hens fed a diet with $30 \%$ whole rye, but the enzyme was not effective when ground rye was used. Supplementation of a diet containing 30\% brewer's dried grains with xylanase positively affected performance and nutrient utilization in broilers (Iyayi and Davies, 2005).

The results of the balance study did not show any significant effect of dietary inclusion level of DDGS or supplementation of the diet containing 20\% DDGS with NSP-hydrolizing enzymes on retention (as \% of intake) and excretion of $\mathrm{N}, \mathrm{Ca}$ and $\mathrm{Zn}$ (Table 3). In diets with 0, 5, 10, 15 and 20\% DDGS, the balances of $\mathrm{N}, \mathrm{Ca}$ and $\mathrm{Zn}$ were similar. In contrast with our results, Spiehs et al. (1999) reported that inclusion of 10 or $20 \%$ mDDGS in diets for growing and finishing swine tended to increase $\mathrm{N}$ excretion. In another study, these authors showed that inclusion of $20 \% \mathrm{mDDGS}$ in the diet had no effect on nitrogen retention (as \% of $\mathrm{N}$ intake), but increased $\mathrm{N}$ excretion (Spiehs et al., 2000).

There was a significant influence of dietary treatment on P balance (Table 3). Dietary inclusion levels of 15 and 20\% mDDGS or 20\% rDDGS decreased P excretion and positively affected $\mathrm{P}$ retention $(\mathrm{P} \leq 0.05)$. It could be speculated, based on literature data, that fermentation increases $\mathrm{P}$ availability in DDGS, possibly through synthesis of microbial phytase (Lumpkins and Batal, 2005). The higher $P$ availability of diets with 15 and 20\% DDGS could be important due to environmental concerns and for economic reasons (phosphorus is an expensive component of poultry diets). Our results correspond with data from experiments on pigs (Spiehs et al., 1999), where inclusion of 10 or $20 \%$ DDGS in a maize-soyabean based diet increased $\mathrm{P}$ retention (as \% of $\mathrm{P}$ intake) and decreased $\mathrm{P}$ excretion. In a later experiment by Spiehs et al. (2000), inclusion of DDGS into a diet had no effect on P retention, but urinary $\mathrm{P}$ excretion in pigs fed a diet with $20 \% \mathrm{mDDGS}$ tended to decrease as compared with a control group $(\mathrm{P} \leq 0.15)$. Apparent total tract digestibility of $\mathrm{P}$ in DDGS fed to growing pigs amounted to $59.1 \%$ and was significantly greater than in maize (Pedersen et al., 2007). Whitney et al. (2001) suggested that DDGS could be an excellent source of available P for growing swine. They showed in slope-ratio analysis, that $\mathrm{P}$ availability in mDGGS was 87.5 and $92.2 \%$, based on $\mathrm{P}$ excretion and $\mathrm{P}$ retention, respectively, as compared with $\mathrm{P}$ availability from dicalcium phosphate. In a study with broiler chickens, Martinez-Amezcua et al. (2004) reported that relative P availability in DDGS was higher than the value estimated from NRC (1994), but there was substantial variability in P availability among different DDGS samples. In a later study, MartinezAmezcua and Parsons (2007) showed that P bioavailability in DDGS (relative to $\mathrm{P}$ in $\mathrm{KH}_{2} \mathrm{PO}_{4}$ ) increases with the duration of heating DDGS. 


\section{CONCLUSIONS}

The results of our study indicate that high dietary level of DDGS could decrease dietary nutrient digestibility and metabolizable energy content, but positively affect phosphorus balance in laying hens. Addition of NSP-hydrolysing enzymes reduces the negative effect of high dietary levels of DDGS on nutrient digestibility.

\section{REFERENCES}

Aman P., Graham H., 1987. Analysis of total and insoluble mixed-linked $(1 \rightarrow 3),(1 \rightarrow 4) \beta$-D-glucans in barley and oats. J. Agr. Food Chem. 35, 704-709

AOAC, 1990. Association of Official Analytical Chemists, Official Methods of Analysis. $15^{\text {th }}$ Edition. Arlington, VA

Englyst H.N., Cummings J.H., 1984. Simplified method for measurement of total non-starch polysaccharides by gas-liquid chromatography of constituent sugars as alditol acetates. Analyst 109, 937-942

European Table of Energy Values for Poultry Feedstuffs, 1989. WPSA, Wageningen (The Netherlands)

Iyayi E.A., Davies B.I., 2005. Effect of enzyme supplementation of palm kernel meal and brewer's dried grain on the performance of broilers. Internat. J. Poultry Sci. 4, 76-80

Jaroni D., Scheideler S.E., Beck M.M., Wyatt C., 1999. The effect of dietary wheat middlings and enzyme supplementation. II: Apparent nutrient digestibility, digestive tract size, gut viscosity, and gut morphology in two strains of leghorn hens. Poultry Sci. 78, 1664-1674

Lazaro R., Garcia M., Aranibar M.J., Mateos G.G., 2003. Effect of enzyme addition to wheat-, barley- and rye-based diets on nutrient digestibility and performance of laying hens. Brit. Poultry Sci. 44, 256-265

Lumpkins B., Batal A., 2005. The bioavailability of lysine and phosphorus in distillers dried grains with solubles. Poultry Sci. 84, 581-586

Lumpkins B., Batal A., Dale N., 2005. Use of distillers dried grains plus solubles in laying hen diets. J. Appl. Poultry Res. 14, 25-31

Martinez-Amezcua M., Parsons C.M., 2007. Effect of increased heat processing and particle size on phosphorus bioavailability in corn distillers dried grains with solubles. Poultry Sci. 86, 331-337

Martinez-Amezcua M., Parsons C.M., Noll S.L., 2004. Content and relative bioavailabilty of phosphorus in distillers dried grains with solubles in chicks. Poultry Sci. 83, 971-976

NRC, 1994. Nutrient Requirements of Poultry. 9th Edition. National Academy Press, Washington

Nyachoti C.M., House J.D., Slonimski B.A., Seddon I.R., 2005. Energy and nutrient digestibility in wheat dried distiler's grains with solubles fed to growing pigs. J. Sci. Food Agr. 85, 2581-2586

Pan C.F., Igbasan F.A., Guenter W., Marquardt R.R., 1998. The effects of enzyme and phosphorus supplements in wheat- and rye-based diets on laying hen performance, energy and phosphorus availability. Poultry Sci. 77, 83-89

Pedersen C., Boersma M.G., Stein H.H., 2007. Digestibility of energy and phosphorus in 10 samples of distillers dried grains with solubles fed to growing pigs. J. Anim. Sci. 85, 1168-1176

Roberson K.D., Kalbfleisch J.L., Pan W., Charbenau R.A., 2005. Effect of corn distiller's dried grains with solubles at various levels on performance of laying hens and egg yolk color. Int. J. Poultry Sci. 4, 44-51 
Smulikowska S., Święch E., Mieczkowska A., 1997. The effect of feeding whole wheat or rye and enzyme supplementation on laying performance, gizzard size and viscosity of intestinal digesta in hens. J. Anim. Feed Sci. 6, 541-547

Spiehs M.J., Shurson G.C., Whitney M.H., 1999. Energy, nitrogen, and phosphorus digestibility of growing and finishing swine diets containing distiller's dried grains with solubles. J. Anim. Sci. 77, Suppl. 1, 188 (Abstr.)

Spiehs M.J., Whitney M.H., Shurson G.C., Nicolai R.E., 2000. Odor characteristics of swine manure and nutrient balance of grow-finish pigs fed diets with and without distiller's dried grains with solubles. J. Anim. Sci. 78, Suppl. 2, 69 (Abstr.)

Świątkiewicz S., Koreleski J., 2006a. Effect of maize distillers dried grains with solubles and dietary enzyme supplementation on the performance of laying hens. J. Anim. Feed Sci. 15, 253-260

Świątkiewicz S., Koreleski J., 2006b. Evaluation of nutritional value of rye distillers dried grains with solubles for laying hens. Pol. J. Nat. Sci., Suppl. 3, 421-426

Świątkiewicz S., Koreleski J., Dai QiuZhong, 2001. Effect of non-starch polysaccharides on bioavailability of inorganic and organic sources of zinc in broiler chickens. Ann. Anim. Sci. 1, 99-111

Whitney M.H., Spiehs M.J., Shurson G.C., 2001. Availability of phosphorus in distiller's dried grains with solubles for growing swine. J. Anim. Sci. 79, Suppl. 1, 108 (Abstr.) 